\title{
Modeling and Analysis of Incoming Raw Materials Business Process: A Process Mining Approach
}

\author{
Mahendrawathi Er*, Hanim Maria Astuti, Dita Pramitasari \\ Surabaya, Indonesia. \\ * Corresponding author. Tel.: +62-31-5999944; email: mahendra_w@is.its.ac.id \\ Manuscript submitted July 10, 2014; accepted January 28, 2015. \\ doi: 10.17706/ijcce.2015.4.3.196-203
}

Information Systems Department, Faculty of Information Technology, Institut Teknologi Sepuluh Nopember,

\begin{abstract}
This paper presents research on implementation of process mining to model and analyze incoming raw materials business processes in a real case company. First the literature is reviewed to understand the state-of-the-art of process mining. Then, survey and observation on the case company are conducted to understand the incoming raw material business process, to determine the goal, focus and scope of process mining implementation and to gather the required data. Subsequently, the event log is created by extracting the database of SAP Enterprise Resources Planning (ERP) Material Management and Warehouse Management Modules. This the event log is then processed with ProM to obtain the business process model. It was found that the actual operation of the business process highly conforms to the standard set by the company as every incoming material is inspected for quality. However, as the material fail the quality inspection, the lead time exceeds the standards. In addition, the most problematic type of material happens to be bought from sole supplier. It is proposed that the company requires to develop long-term strategic partnership with the supplier to gain win-win solution for both parties.
\end{abstract}

Key words: Case study, heuristic miner, process mining, quality inspection.

\section{Introduction}

In today's business environment the use of information systems in supporting organization's business processes have become imperative [1]. The emergence of enterprise systems such as ERP, customer relationship management (CRM) and supply chain management (SCM) enables companies to integrate their inter-related business processes. In addition, the use of such systems enables companies to obtain record of the systems usage i.e. event log that provides rich data which can be used to model, analyze and improve the existing business process. Process mining has emerged as an active stream of research field that serves this purpose.

Research in process mining can be divided into several streams. First, a lot of work have been done in developing algorithm to model event log data, both with global or local approach [2]-[4]. Secondly, some of the attention also focused on obtaining high quality event log as input for the process mining [1], [5]. The third stream of literature has addressed the issue of performance dimensions to evaluate the process mining algorithm [6], [7]. The final stream of literature reports the implementation of process mining in real cases. The last area is still lacking in the current literature. The work provided by [8] is among a few research that use process mining in modeling and analyzing real problem.

This paper reports the research conducted in implementing process mining to model and analyze 
incoming raw materials business processes. The case company is a subsidiary of a multinational company producing shoes which implements SAP ERP to support their business processes. Incoming raw business processes are taken as the case study since the supply of high quality materials at the right time for production is crucial and this can be achieved through quality inspection process of incoming raw materials. At the end of the paper, an analysis of the incoming raw materials business process will be provided. In addition to that, the strategies to address the problem are proposed according to the analysis.

\section{State-of-the-Art of Process Mining}

\subsection{Business Process Modelling}

Various techniques have been developed to document processes in business organization. Traditionally, organization document their organization's chart to describe functions within the organization. But this traditional approach fail to describe the business process within the organization. To fill this gap, many works have been done to model business processes [9]. A business process model - a graphical visualization to represent the business processes in a company - cannot be entirely accurate or complete because every modeler have different perspectives. Several techniques developed to compensate the drawbacks, those are flowchart, data flow diagram, role activity diagram, role interaction diagram, Gantt chart, Colored Petri Net, object oriented method, and workflow technique [10].

\subsection{Process Mining and Its Algorithm}

Process mining is a field of study that combines the concept of business process model and analysis. The basic notion of process mining is to discover, monitor and improve real and not assumed processes, by extracting knowledge from the real time event log of the systems using particular algorithm. Process mining can be used as a tool to understand how process or people really works and also to identify deviation between process execution and pre-defined process in order to push for business process engineering (BPR) [11].

There is a strong correlation between the algorithm and the type of problems that the algorithm can handle successfully [12]. The algorithm used depends on the approach chosen [13]. Heuristic miner is one of the algorithms developed from local approach, which is an extension from Alpha algorithm [11]. The local approach for process mining will construct business process model from local relation between individual activities in the log. Global approach, on the other hand, constructs the model after the entire process is completely connected. Each algorithm has its characteristics that differentiate one and others [4].

\section{Methodology}

The first step to conduct this research is conducting a survey in the case company to obtain general information about the incoming materials business process. The survey is done through interview and direct observation at the company. The respondents are the managers of raw material warehouse and SAP functional. In this stage, the goal, focus and scope of the process mining implementation are defined. In addition, the Case IF, attributes of the SAP tables to be extracted to obtain the event log is also determined. The entire survey and data collection is done in one month. The next step is the extraction of the database and the formation of event log. The event log is standardized in. MXML (Mining XML) format using Nitro application. After the standard log is obtained, it was then processed using ProM tool. The process mining algorithm used here is Heuristic Miner. The process model is then analyzed.

\section{Business Process Modelling}

\subsection{Case Description}


The case company is a manufacturer of an international company producing leather shoes. The company in Indonesia produces the upper components as well as finished products based on forecast provided by the headquarters. The company has implemented SAP ERP to support their business process including warehouse management module (WM) which is integrated with material management (MM) to help the company run the procurement, stocking and delivering the raw material for production.

The company has two warehouse and two division that handle raw material and finished products separately. The division that manages raw materials i.e. incoming raw material, storing, and delivering for production, is called Warehouse Division whereas the finished product is handled by production distribution center (PDC). In this paper we will focus on the incoming materials processes conducted by warehouse division.

\subsection{Business Process}

Based on the interview and observation, the goal of the process mining implementation is to identify deviation in the incoming material business process and propose recommendation for improvement. The focus will be on the raw materials that must go through quality inspection process. Incoming materials business processes includes the following activities:

1) Purchase order (PO), this is a formal request or instruction from a purchasing organization to a vendor or a plant to supply or provide a certain quantity of goods or services at or by a certain point in time (1). This activity is the trigger of incoming raw materials business process.

2) Goods receipt, this is an activity to accept the raw material based on PO.

3) Quality inspection. This activity is intended to check whether sample of materials received from the vendor satisfies the quality standard set by the company. The QI can be done once for each material receipt or it can be done in several stages.

4) Unrestricted stock. Material that pass the QI is put as Unrestricted Stock and is ready to be delivered to the shop as requested by the production department.

5) Blocked stock. Not all incoming raw materials pass the QI. Material that does not meet the standard is put in blocked stock and cannot be used for production. For each blocked stock, Warehouse division must conduct additional activities such as communicating to the procurement department, vendor, an even destroying the materials.

\subsection{Database Extraction and Event Log Standardization}

After obtaining a good understanding of activities in the business process, the next step is obtaining the event log. However, the company does not activate their event log functions. Therefore, the log related to the business process must be extracted from the database. To do so, first, the activities must be mapped with the SAP tables that store information on the related activities. Results of the mapping is shown in Table 1 which indicates the involvement of two modules (i.e. MM and WM) to extract raw materials data.

Table 1. Mapping of Activity and Table

\begin{tabular}{cllc}
\hline \hline No. & \multicolumn{1}{c}{ Activity } & \multicolumn{1}{c}{ Document } & Table \\
\hline 1. & Purchase Order & Purchase Order (MM) & EKKO; EKPO \\
\hline 2. & Goods Receipt & Materials Document (MM) & MSEG \\
\hline 3. & Quality Inspection & Transfer Order (WM) & LTAK; LTAP \\
\hline 4. & Unrestricted Stock & Materials Document (MM) & MSEG \\
\hline 5. & Blocked Stock & Materials Document (MM) & MSEG \\
\hline \hline
\end{tabular}


The next step is determining attributes from each table. In this research the attribute that is suitable with the case is chosen. Results from the extraction is saved in 5 MS. Excel files as follow: 1) File List Material Document-Goods Receipt; 2) File List Material Document-Unrestricted Stock, 3) File List Material Document-Blocked Stock, 4) File List Document Transfer Order and 5) File List Document Purchase Order. These files are combined into one file to create the event log. The Case id used in this case is a combination of material number, size, PO number, and sequence of material being put into the rack (unrestricted stock or blocked stock).

\subsection{Business Model and Scenarios}

The constructed event log is then transformed into .MXML before being processed with ProM tool. The process mining algorithm used in this research is Heuristic Miner because it was proven to yield a good performance in modelling various event logs. The parameter used is default parameter because the experiment result of changing the parameter shows that it does not affect the process model. The result of the process model is shown in Fig. 1.

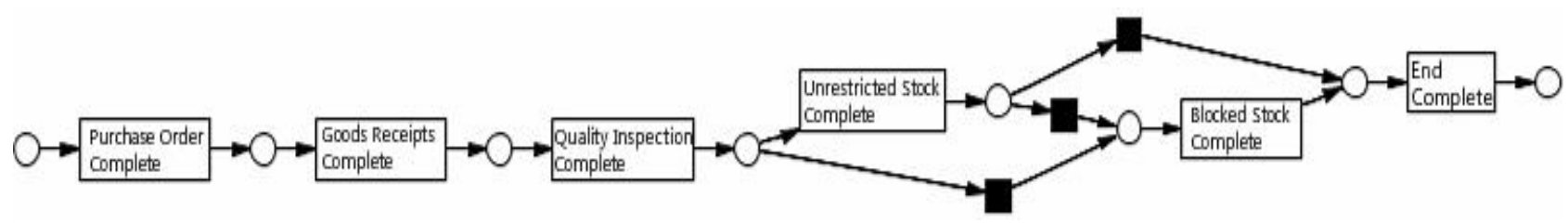

Fig. 1. Incoming raw material process model.

Based on the process model, three business scenarios are obtained. Table 2 lists the scenarios and their lead time and frequency.

Table 2. Business Scenarios

\begin{tabular}{llll}
\hline \hline Scenario & \multicolumn{1}{c}{ Log Trace } & Lead time & Frequency \\
\hline \multirow{2}{*}{$\begin{array}{l}\text { Purchase Order } \rightarrow \text { Goods Receipt } \rightarrow \text { Quality Inspection } \rightarrow \\
\text { Unrestricted Stock } \rightarrow \text { End }\end{array}$} & $\begin{array}{l}\text { 69 days 44 } \\
\text { minutes }\end{array}$ & 3294 \\
\hline 2 & $\begin{array}{l}\text { Purchase Order } \rightarrow \text { Goods Receipt } \rightarrow \text { Quality Inspection } \rightarrow \\
\text { Blocked Stock } \rightarrow \text { End }\end{array}$ & 72 days 20 hours & 130 \\
\hline 3 & $\begin{array}{l}\text { Purchase Order } \rightarrow \text { Goods Receipt } \rightarrow \text { Quality Inspection } \rightarrow \\
\text { Unrestricted Stock } \rightarrow \text { Blocked Stock } \rightarrow \text { End }\end{array}$ & 79 days 4 hours & 44 \\
\hline & TOTAL & 3468 \\
\hline
\end{tabular}

According to Table 2, scenario 1 appears to be the normal scenario that happens most frequent and takes faster to finish. On the other hand, scenario 3 is the least frequent scenario but it takes longest time to finish. Scenario 1 appears when the incoming material pass the QI test and therefore classified as unrestricted stock. Scenario 3 has the longest lead time compared to the other two scenarios because after the material is released to the shop floor for assembly, it does not meet the quality standard.

\section{Analysis}

This section presents findings and analysis which comprised of three aspects: conformance of the quality inspection process, bottleneck analysis and impact of the raw material quality.

\subsection{Conformance of Quality Inspection}


One of the uses of process mining is to discover deviation of real process to the standard process. In terms of raw materials warehouse, there are two standards set by the company:

1) All incoming materials from vendor must go through Quality Inspection process to ensure that the material meet the quality standard set by the company.

2) Lead time for quality inspection activity must be within days, depending on the quality test done for the material.

Fig. 2(a) and Fig. 2(b) respectively show the process model created from the event log using Heuristic Miner Algorithm complete with frequency and lead time of each activity. The Fig. 2(a) can be used to identify the frequency of instances that pass the QI activities whereas Fig. 2(b) can be used to check the performance of the business process in terms of lead time.

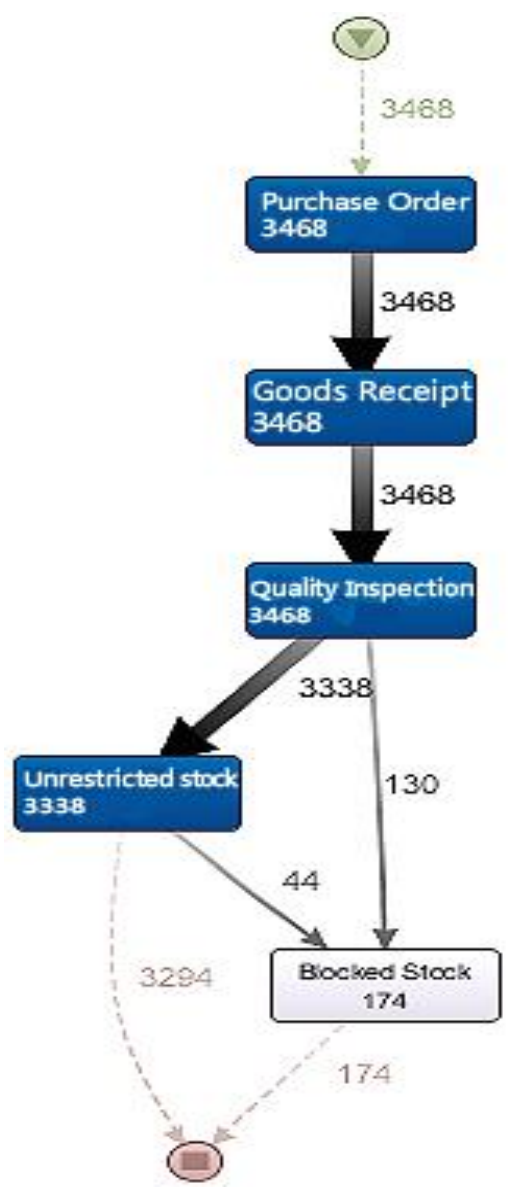

(a) Business model with frequency of instances;

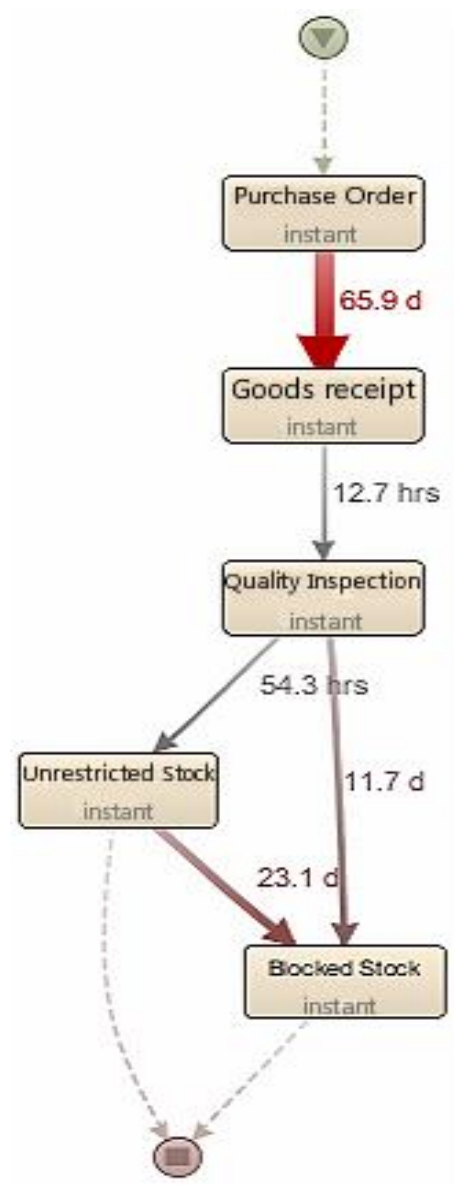

(b) Business model with lead time.

Fig. 2. Frequency and lead time of incoming raw material business process.

According to Fig. 2(a), from 3468 instances in the incoming materials event log, 3294 instances are categorized as unrestricted stock whereas 174 instances are categorized as blocked stock. This means that QI activities are done for every incoming material in the warehouse so it can be said that the operational business process highly conform to standard number 1 set by the company.

Fig. 2(b) shows that the average lead time from QI to unrestricted stock is 54.3 or close to 3 days. This is in accordance with the standard determined by the company where QI activities must be completed within days. However, the average lead time for QI to blocked stock is 11.7 days or over one normal week. This does not satisfy the standard because material categorized as blocked stock will be automatically subjected to more inspection tests compared to those that is categorized as unrestricted stock. 
Significantly longer time to finished unrestricted stock means that this activity is the bottleneck in the incoming materials process. Bottleneck in the business process is shown in Fig. 3 which is marked by a pink colored place (the third cycle from the left). The more serious consequence of blocked stock is that it can delay the production of products requiring the material. The company has experienced delay in production because the materials did not pass the quality inspection. Thus, the company has to pay more attention on these blocked stock.

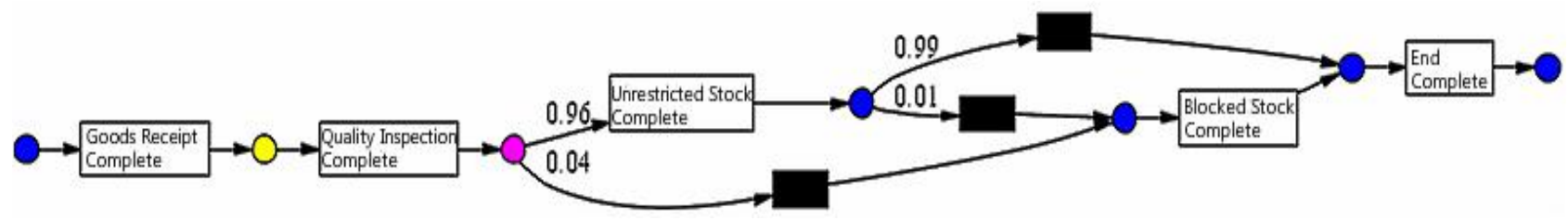

Fig. 3. Bottleneck in incoming materials activities.

\subsection{Blocked Stock}

Further identification of the blocked stock shows that the type of material that most frequently fail to pass QI is Shank Plastic Touch 25S and Shank Plastic \& Heel Box Touch 45 S. Shank and Heel are materials related to the use of jig by injection. Out of 174 blocked stock instances in the data, $78.16 \%$ is Shank. When Shank is received by warehouse division usually the hole is covered by PU (Polyurethane). Thus, modification must be done before the quality inspection. This means that there is greater chance for this material to fail the quality inspection and classified as blocked stock.

Having identified the material type, analysis can also be done to identify vendor that contributes to most frequent blocked stock. In this case, it was found that supplying vendor for Shank Plastic Touch $25 \mathrm{~S}$ and Shank Plastic \& Heel Box Touch 45 S is PT. GT. Coincidentally, the company only has this vendor as a sole supplier for both materials. The reason that the company applies single sourcing strategy is because the products require materials with high conformity in terms of color, design and dimension. For Shank, vendor must conform to these following requirements:

- Material combination used differ from one model of shoes to another.

- Shank should not wash to other materials.

- Design must perfectly fit the shank mold.

- Must fit exactly so when the PU (Polyuretane) injection will remain as the mold.

- Does not contain hazardous materials.

This high requirement makes it hard for the company to find alternative supplier. So far the company attempts to find win-win solution for both parties in solving the quality problems. They expect their vendor to improve the quality of their materials to satisfy the company's standard.

\subsection{Discussion}

Findings from implementation of process mining to model incoming raw material business process highlights two main things. First, the fact that the occurrence of blocked stocked potentially lengthen the entire process means that the company should treat these materials with great care. When the materials fail to pass the QI test then it has to be examined: whether there will be requirement for that material in production and if there is still enough stock for the material in the warehouse to satisfy the production requirement. This has to be done to predict for potential delay in production. If there is a high chance that the blocked stock will delay production then the company must have contingency plan to deal with the situation such as speed up the process of the blocked stock. 
Secondly, the problem of material quality must also be solved from the source i.e. the vendor. It was found that the case company typically applies single sourcing strategy with one supplying vendor for each type of material. This also applies for Shank, which frequently fails QI material. Shank is considered a highly specific, non-substitutable material. Each type of shoes will require different types of shank. This means vendor supplying shank can be classified as critical strategic supplier.

Company must create long-term partnership with their Critical strategic supplier. Many success stories have highlighted the value of partnership with their critical vendor. The company can provide technical assistance for the vendor to improve their product quality. They can also be included in Research and Development team to ensure that they know the standard required. This way both parties can gain benefit from the partnership.

\section{Concluding Remarks}

This paper reports the implementation of process mining in modelling and analyzing incoming material business process in a real case. One of the main challenge is to obtain the event log. In this case the log must be extracted from SAP database using TCode LT24 (list transfer order), MB51 (list material document), and SQ00 (list purchase order). The results are combined into an event log with the case id, activities, timestamp, material name, size and vendor as attributes. Analysis from the process model shows that in general the actual incoming raw material process highly conforms to the standard because every incoming material must go through Quality Inspection process. However, when the material fail to pass the QI process then additional tests must be done, which eventually lengthen the entire process and potentially delay production. The analysis also found the most problematic material as critical material and the supplying vendor as critical strategic supplier.

\section{References}

[1] Buijs, J. C. A. M. (2010). Mapping data sources to XES in a generic way. Master thesis, Dept. of Mathematics and Computer Science, Eindhoven University of Technology, Eindhoven.

[2] Medeiros, A. K. A., Weijters, A. J. M. M., \& Aalst, W. M. P. van der (2006). Genetic process mining: An experimental evaluation. Journal of DataMining and Knowledge Discovery, 14, 245-304.

[3] Wen, L., Aalst, W. M. P. van Der, Wang, J., \& Sun, J. (2007). Mining process models with non-free-choice constructs. Journal Data Mining and Knowledge Discovery, 15(2), 145-180.

[4] Weijters, A. J. M. M., Aalst, W. M. P. van Der, \& Medeiros, A. K. A. de (2006). Process mining with the heuristics miner-algorithm. Tech. Rep. WP 166 (pp. 1-34). Technische Universiteit Eindhoven.

[5] Piessens, D. (2011). Event log extraction from SAP ECC 6.0. Master thesis, Dept. of Mathematics and Computer Science, Eindhoven University of Technology, Eindhoven.

[6] Rozinat, A., Medeiros, A. K. A. de, Gunther, C., Weijters, A. J. M. M., \& Aalst, W. M. P. van der (2007). Towards an evaluation framework for process mining algorithms. BPM Center Report BPM-07-06.

[7] Rozinat, A., \& Aalst, W. M. P. van der (2009). Conformance checking of processes based on monitoring real behavior. Information Systems, 33(1), 64-95.

[8] Weerdt, J. de, Schupp, A., Vanderloock, A., \& Baesens, B. (2013). Process mining for the multi-faceted analysis of business processes - A case study in a financial services organization. Computers in Industry, 64, 57-67.

[9] Carnaghan, C. (2006). Business process modeling approaches in the context of process level audit risk assessment: An analysis and comparison. International Journal of Accounting Information Systems, 170-204.

[10] Aguilar-Saven, R. S. (2004). Business process modelling: Review and framework. International Journal 
of Production Economics, 90, 129-149.

[11] Weijters, A. J. M. M., \& Aalst, W. M. P. van der (2003). Rediscovering workflow models from event-based data using little thumb. Journal Integrated Computer-Aided Engineering, 10(2), 151-162.

[12] Aalst, W. M. P. van der, Weijters, A. J. M. M., \& Maruster, L. (2004). Workflow mining: Discovering process models from event logs. IEEE Transactions on Knowledge and Data Engineering, 16(9), 1128-1142.

[13] Saravanan, M., \& Rama, S. (2011). Application of mining algorithms using ProM and Weka tools. International Journal of Computer Science and Technology, 331-337.

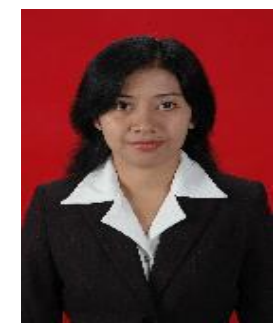

Mahendrawathi Er was born in Denpasar, on October 11, 1976. Mahendrawathi received her bachelor degree in industrial engineering from Institut Teknologi Sepuluh Nopember, Surabaya, Indonesia and a master degree in operations management and manufacturing systems and a doctoral degree in manufacturing engineering and operations management both from Nottingham University, Nottingham, United Kingdom. She briefly worked as a research assistant for value improvement through Virtual Aeronautics Collaborative Enterprise (VIVACE), a project funded by the European Union. Since 2006, she became a lecturer in Information Systems Department, Institut Teknologi Sepuluh Nopember, Surabaya, Indonesia. She teaches among others supply chain management, enterprise resource planning, enterprise models, and e-business. She is a member of Decision Support Systems and Business Intelligence Research Lab. Her research interests are supply chain management, business process management and enterprise systems. Dr. Mahendrawathi has published her work in international journals and conferences.

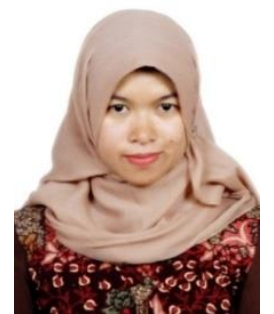

Hanim Maria Astuti is currently an active member of the Planning and Development of Information Systems Laboratory in the Department of Information Systems, Institut Teknologi Sepuluh Nopember, Indonesia. She earned her B.S. degree in information systems from Institut Teknologi Sepuluh Nopember, Indonesia; and M.Sc. degree in management of technology from Delft University of Technology, the Netherlands. She has conducted some research projects granted by National Research Program, The Ministry of Higher Education, Indonesia, and has published some conference papers. Her research interests include service innovation, business process management and IT risk \& quality management.

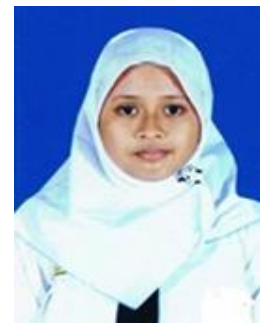

Dita Pramitasari was born in Sukoharjo, on December 21, 1992. She has been listed as a bachelor student in the Information Systems Department, Institut Teknologi Sepuluh Nopember, Surabaya since 2010. Currently, she is a member of the Decision Support Systems and Business Intelligence Research Laboratory. She is now working on her final project in process mining. This paper is a part of her final project which was her gate to graduate from Information Systems Department in 2014. 